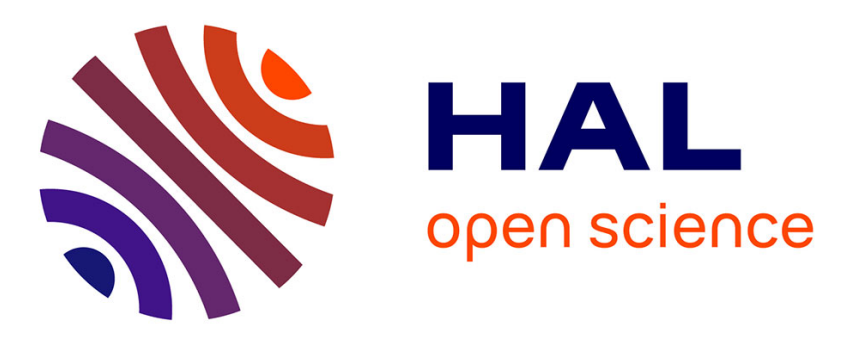

\title{
Implicit measures of beliefs about sport ability in swimming and basketball
}

Nicolas Mascret, Jean-Louis Falconetti, François Cury

\section{To cite this version:}

Nicolas Mascret, Jean-Louis Falconetti, François Cury. Implicit measures of beliefs about sport ability in swimming and basketball. European Journal of Sport Science, 2016, 16 (3), pp.358 - 364. 10.1080/17461391.2015.1080304. hal-01649402

\section{HAL Id: hal-01649402 \\ https://hal-amu.archives-ouvertes.fr/hal-01649402}

Submitted on 28 Nov 2017

HAL is a multi-disciplinary open access archive for the deposit and dissemination of scientific research documents, whether they are published or not. The documents may come from teaching and research institutions in France or abroad, or from public or private research centers.
L'archive ouverte pluridisciplinaire HAL, est destinée au dépôt et à la diffusion de documents scientifiques de niveau recherche, publiés ou non, émanant des établissements d'enseignement et de recherche français ou étrangers, des laboratoires publics ou privés. 


\section{European Journal of Sport Science}

ISSN: 1746-1391 (Print) 1536-7290 (Online) Journal homepage: http://www.tandfonline.com/loi/tejs20

\section{Implicit measures of beliefs about sport ability in swimming and basketball}

\section{Nicolas Mascret, Jean-Louis Falconetti \& François Cury}

To cite this article: Nicolas Mascret, Jean-Louis Falconetti \& François Cury (2015): Implicit measures of beliefs about sport ability in swimming and basketball, European Journal of Sport Science, DOI: 10.1080/17461391.2015.1080304

To link to this article: http://dx.doi.org/10.1080/17461391.2015.1080304

曲 Published online: 10 Sep 2015.

Submit your article to this journal $\widetilde{ }$

Џll Article views: 7

Q View related articles \ulcorner

View Crossmark data $₫$ 


\title{
ORIGINAL ARTICLE
}

\section{Implicit measures of beliefs about sport ability in swimming and basketball}

\author{
NICOLAS MASCRET, JEAN-LOUIS FALCONETTI, \& FRANÇOIS CURY
}

Aix Marseille Université, CNRS, ISM UMR 7287, 13288 Marseille, France

\begin{abstract}
Sport ability may be seen as relatively stable, genetically determined and not easily modified by practice, or as increasable with training, work and effort. Using the Implicit Association Test (IAT), the purpose of the present study is to examine whether the practice of a particular sport (swimming or basketball) can influence automatic beliefs about sport ability in these two sports. The IAT scores evidence that swimmers and basketball players automatically and implicitly associate their own sport with training rather than genetics, whereas non-sportspersons have no significant automatic association. This result is strengthened when perceived competence and intrinsic motivation in swimming or basketball are high.
\end{abstract}

Keywords: Implicit association test, beliefs, sport ability, implicit theory, perceived competence, intrinsic motivation

\section{Introduction}

As defined by Dweck (1986) and Dweck and Leggett (1988), implicit theories are personal beliefs about the changeability of ability. People with an incremental theory see ability as an acquirable skill, improvable through practice and effort. People with an entity theory see ability as fixed, a gift, a talent, and they think that they cannot do very much to modify this initial ability. Dweck, Chiu, and Hong (1995) suggested that incremental and entity beliefs are an integral part of many life domains. Subsequently, researchers have investigated entity and incremental beliefs in the physical activity domain (e.g. Biddle, Wang, Chatzisarantis, \& Spray, 2003; Sarrazin, Biddle, Famose, Cury, Fox, \& Durand, 1996). Entity theorists consider sport ability relatively stable, genetically determined and not easily modified by practice, whereas incremental theorists think that they can increase their sport ability with training. People can have simultaneously an entity and an incremental theory if they believe that sport achievement depends both on genetics and training. The physiological reality in sport is indeed that sport ability depends on initial genetic characteristics (e.g. height or heart and lung functions) and regular training
(Blimkie \& Sale, 1998). In order to identify implicit theories of sport ability, Sarrazin et al. (1996) created the first scale called Conceptions of the Nature of Athletic Ability Questionnaire (CNAAQ), which included six first-order factors (stable, gift, general, learning, incremental and specific). Even if some significant results were evidenced (e.g. Cury, Da Fonséca, Rufo, \& Sarrazin, 2002), some of the subscales reported poor reliability. Consequently, Biddle et al. (2003) revised the initial measure. In this questionnaire, named CNAAQ-2, two higher order factors were evidenced, underpinned by beliefs that athletic ability is stable and a gift (entity) and beliefs that ability can be improved and developed through work and effort (incremental). In the sport and physical education literature, incremental and entity theories were, respectively, linked with adaptive and maladaptive outcomes. Each belief has distinct effects on motivation. Whereas entity beliefs predicted amotivation towards physical education and sport (Biddle et al., 2003), reduced effort (Chen et al., 2008) or self-handicapping (Ommundsen, 2001), incremental beliefs about athletic ability were positively linked with enjoyment of physical activity in youth (Biddle et al., 2003; Wang \& Biddle, 2001), intrinsic

Correspondence: Nicolas Mascret Aix Marseille Université, CNRS, ISM UMR 7287, 163 avenue de Luminy, 13288 Marseille Cedex 9, France. E-mail: nicolas.mascret@univ-amu.fr 
motivation (Moreno, Gonzalez-Cutre, Martin-Albo, \& Cervello, 2010), rejection of self-handicapping (Ommundsen, 2001) and concentration (Ommundsen, Haugen, \& Lund, 2005).

Furthermore, despite their validity and reliability, self-report measures are shown to be subject to social desirability (e.g. Crosby, Bromley, \& Saxe, 1980; Crowne \& Marlowe, 1960), which is the desire of respondents to be perceived positively. Consequently, they may answer questions in order to be viewed favourably by others, which may be a potential source of distortion of measures with questionnaires (Greenwald \& Banaji, 1995). Therefore, even if there may be cultural variations, it may be difficult for some sportspersons to admit that they endorse an entity theory and to admit that they think that sport ability is for them essentially linked with genetic predispositions, for fear of sounding pretentious or conversely confessing incompetence. In studies on implicit theories of sport ability, explicit incremental scores were always higher than entity scores (e.g. Biddle et al., 2003; Cury et al., 2002). Some implicit measures have been created to overcome this problem. For example, the Implicit Association Test (IAT) provides a computer-based measure of the strengths of automatic associations of concepts, in order to evaluate implicit cognitive constructs (Greenwald, McGhee, \& Schwartz, 1998). Implicit attitudes are manifest as actions or judgements that are under the control of automatically activated evaluation, without the performer's awareness of that causation (Greenwald \& Banaji, 1995). But, to date, no IAT exists to highlight implicit theories of sport ability. Investigations of implicit theories in the physical domain use explicit measures and a cross-sectional correlational approach.

The aim of the present study is not to underscore the validity of self-reported measures as the main reason for the use of implicit measurements. Measures of implicit cognition differ from selfreported ones in that they can reveal mental associations without requiring an act of introspection (Nosek, Greenwald, \& Banaji, 2005). Works on the relationship between explicit and implicit measures have shown that the unconscious and the conscious may proceed independently and not be related, or could be positively associated (e.g. Hofmann, Gawronski, Gschwendner, Le, \& Schmitt, 2005). Another reason for conducting this study is, therefore, to show that there can be an automatic association between the between the type of sport and implicit beliefs. So, we can then address the question of the place of these automatic processes in commitment and persistence in a physical activity. Consequently, the main purpose of the present study was to test, with implicit measures, whether persons practising a specific sport in competition implicitly associated their own sport with training or genetics.

\section{Method}

\section{Pilot tests and stimuli}

In a pilot study, 94 undergraduates in a Sport Education class in France rated 24 sports according to their degree of association with "genetics" and with "training", using 2 scales from 1 (not associated at all) to 7 (strongly associated). The two sports with the most extreme evaluation were retained. Swimming was the sport most associated with training $(M=$ 6.19, $\mathrm{SD}=1.10$ ), which is in line with Costill et al.'s (1991) work evidencing the important training component in swimming. Basketball was the sport most associated with genetics $(M=5.23, \mathrm{SD}=$ 1.52), because tall players are over-represented in this sport. Consequently, swimming and basketball were the two sports selected for the present study. Football (soccer), swimming, tennis, basketball, volleyball and dance were the sports most represented among the sample.

To build the IAT, 32 nouns were used as lexical stimuli. Fifteen French lecturers specialising in the sports domain suggested terms which are associated with genetics, training, swimming and basketball. Twelve nouns were selected for each category. These words were then rated according to their degree of linkage with the respective concepts on a 7-point scale ( $1=$ not at all, $7=$ extremely $)$ by 85 pilot participants who were not included in the actual study. For each concept, the eight words with the most extreme evaluation were used for the study (see Table I). Word length was controlled by counting the numbers of letters, and there were in French language no significant differences $(t(14)=1.16, p=.26)$ between genetic words $(M=9.13, \mathrm{SD}=1.73)$ and training words $(M=$ $10.25, \mathrm{SD}=2.12)$, and no significant differences $(t(14)=0.84, p=.42)$ between swimming words $(M=$ $7.00, \mathrm{SD}=1.51)$ and basketball words $(M=6.50$, $\mathrm{SD}=0.76)$. The genetic words were rated as more genetics-related $(M=5.75, \mathrm{SD}=1.88)$ than the training words $(M=2.43, \mathrm{SD}=1.73, t(7)=16.70, p \leq .001)$, and the swimming words were rated as more swimming-related $(M=6.75, \mathrm{SD}=0.82)$ than the basketball words $(M=1.74, \mathrm{SD}=1.53, t(7)=68.54, p=<.001)$. Based on these ratings, the 32 words were selected and used as lexical stimuli.

\section{Participants, design and procedure}

Data were collected in France from 183 voluntary participants (93 female, 90 male, mean age $=21.02$, 
Table I. Terms used in the IAT (translated from French)

\begin{tabular}{llll}
\hline Swimming & Basketball & Training & Genetics \\
\hline Crawl & Hoop & Work & Birth \\
Swimming-pool & Dribbling & Preparation & Chromosomes \\
Diving board & Pass & Warm-up & Maternity \\
Aquatic & Court & Repetition & Descendants \\
Pool & Backboard & Method & Cloning \\
Breaststroke & Parquet & Recovery & Hereditary \\
Goggles & Gymnasium & Progression & Origins \\
Bathing cap & Ball & Improvement & Cell \\
\hline
\end{tabular}

$\mathrm{SD}=3.03$ ). Permission was granted by the Dean of the faculty to contact students directly. Students participated voluntarily and ethical approval was granted for the protocol of the study by the institutional review board of the university. Immediately after the protocol, participants were briefed about the aims of the study.

Two groups of sportspersons were constituted according to the sport they practised: swimming (45 participants, 14 female, 31 male, mean age $=21.77$, $\mathrm{SD}=3.53$, mean time of practice $=6.71$ hours per week, $\mathrm{SD}=2.73$ ) and basketball (44 participants, 16 female, 28 male, mean age $=20.64, \mathrm{SD}=2.47$, mean time of practice $=8.00$ hours per week, $\mathrm{SD}=$ 2.84). All the sportspersons (89 participants) were licence-holders in a club affiliated to a sports federation and practised their sport competitively. They were not national-level sportspersons, professionals or athletes with a physical or mental disability. One group of non-sportspersons was also constituted with 94 participants. It is difficult to assess physical activity, because reports are limited by the researcher's opportunity to observe the physical activity of the subject, so self-report is needed - with caution (Sallis \& Saelens, 2000). Firstly, following Slutzky and Simpkins (2009), participants categorised as non-sportspersons declared they were not licenceholders and did not practise organised and formal sport activities, with a regular schedule. Secondly, in Wang, Chatzisarantis, Spray, and Biddle's (2002) work, the lower category of the duration of time that participants devoted to informal sport activities was less than one hour per week. In the present study, they declared that they did not practise informal sports or did so less for than one hour in a month. Finally, participants who had been sportspersons and competitors in the past, whatever the sport, were excluded from the study.

The Genetic-training IAT (GT-IAT) was performed on a personal computer with a $15^{\prime \prime}$ monitor using Inquisit 4 software. Then, the participants completed four self-report scales in order to measure interest and perceived competence in swimming and basketball. Performing IAT before self-report measures does not impact results (Nosek et al., 2005). To conduct the IAT, participants placed one finger on the $E$ key (left key) of the AZERTY keyboard and another finger on the $I$ key (right key). The IAT consisted of seven stages of word categorisation trials. In the first training block, they were instructed to respond as quickly and accurately as possible by pressing a key each time an item that represented the category genetics (e.g. chromosomes, cloning) appeared in the centre of the screen, or the other key each time an item that represented the category training (e.g. warm-up, improvement) appeared. Then, an identical procedure was followed with swimming and basketball words (Greenwald et al., 1998). In combined discrimination tasks, two of the four categories were paired onto the same response key. In the first condition (blocks 3 and 4), swimming and training words shared the same response key, and the other one was used with basketball and genetics words. In the second condition (blocks 6 and 7), the key assignments of the swimming and basketball categories were switched. Block 5 was used for training trials. The blocks were counterbalanced between subjects to avoid order effect. According to the procedures recommended by Greenwald, Nosek, and Banaji (2003), trials higher than $10,000 \mathrm{~ms}$ were deleted. No participant had more than $10 \%$ of trial with latency more than $3000 \mathrm{~ms}$, so all were included in the final sample.

We study the difference in response latency between the average speed of response to swimmingtraining items and basketball-genetic when they were paired together, and conversely. The difference was taken as an implicit assessment of preference. Positive scores indicated stronger association of swimming with training than with genetic, and stronger association of basketball with genetic than with training.

\section{Measures}

Genetics-training-IAT. We used the GT-IAT presented earlier. An IAT score, $D$, was calculated using the algorithm of Greenwald et al. (2003). We 
analysed each measure of automatic evaluation by taking a difference score between performance (i.e. average response latency) when swimming was paired with genetic attributes and performance when swimming was paired with training attributes. Following Greenwald et al. (2003), D scores are classified with slight, medium and strong labels.

Perceived competence and intrinsic interest. These two subscales were assessed with Durand, Cury, Sarrazin, and Famose's (1996) French translation of the Intrinsic Motivation Inventory (McAuley, Duncan, \& Tammen, 1989). In the formulation of all items in the present study, the term "sport" was changed to "swimming" or "basketball". Participants responded to the four perceived competence items (e.g. "I think I am pretty good at swimming/basketball”). Internal consistencies were good for perceived competence in swimming $(\alpha=.89)$ and basketball $(\alpha=.88)$. Participants responded to the four interest items (e.g. "I enjoy swimming/basketball") using a 1 (strongly disagree) to 5 (strongly agree) scale. Internal consistencies were high for interest in swimming $(\alpha=.87)$ and basketball $(\alpha=.89)$.

\section{Results}

In line with Greenwald et al. (2003), the IAT score revealed no significant association between swimming and training, and between basketball and genetics $(D$ $=-0.09, \mathrm{SD}=0.45)$ for the entire population, with no effect of gender $(F(1,181)=2.03, p=.16)$. Three groups were constituted in the present study: swimmers, basketball players and non-sportspersons. A one-way ANOVA conducted on IAT scores revealed a significant effect of type of sport $(F(2,180)=47.49$, $p<.0001)$. Firstly, the IAT score revealed for swimmers a slight to medium positive association between swimming and training $(D=0.24)$. The Newman-Keuls test showed that swimmers more often associated swimming with training than basketball players $(p<.001)$ and non-sportspersons $(p<.001)$. Secondly, the IAT score revealed for basketball players a medium to strong negative association between basketball and genetics $(D=-0.51$, $\mathrm{SD}=0.38$ ). The Newman-Keuls test evidenced that basketball players more often associated basketball with training than swimmers $(p<.001)$ and nonsportspersons $(p<.001)$. Finally, the IAT score revealed no significant association between swimming, basketball, training and genetics for nonsportspersons $(D=-0.04, \quad \mathrm{SD}=0.34)$. Table II provides all the descriptive statistics of $D$ score among the five groups.

The GT-IAT score was positively correlated with interest and perceived competence in swimming $(r=.23, p<.01$ and $r=.24, p<.001$, respectively) and negatively related with interest and perceived competence in basketball $(r=-.19, p<.01$ and $r=$ $-.28, p<.001$, respectively). When participants have high perceived competence and interest in swimming or basketball, they tend to automatically associate this sport with training rather than genetics. Table III provides the full correlations. Four one-way ANOVAs successively run on interest and perceived competence in swimming, and interest and perceived competence in basketball scores evidenced a significant effect of type of sport $(F(2,180)=27.83$, $p<.001, F(2,180)=21.27, p<.001, F(2,180)=$ $60.18, p<.00001$ and $F(2,180)=70.84, p<.001$, respectively). Newman-Keuls tests revealed that swimmers scored higher on interest and perceived competence in swimming than basketball players and non-sportspersons. Other Newman-Keuls tests revealed that basketball players scored higher on interest and perceived competence in basketball than swimmers and non-sportspersons. All Newman-Keuls tests were significant at $p<.001$. In line with these results, non-sportspersons always have lower interest and perceived competence in swimming and basketball than swimmers and basketball players in their own sport. Table IV provides all the descriptive statistics.

\section{Discussion}

The present study firstly evidenced that persons practising swimming or basketball in competition implicitly associated their own sport with training rather than genetics, whereas non-sportspersons have no significant implicit association. The automatic association between training and swimming for swimmers, and between training and basketball for basketball players, was in line with previous

Table II. Descriptive statistics of $D$ score among groups

\begin{tabular}{lrr}
\hline Groups & $M$ & SD \\
\hline 1. Swimmers & 0.24 & 0.42 \\
2. Basketball players & -0.51 & 0.38 \\
3. Non-sportspersons & -0.04 & 0.34 \\
\hline
\end{tabular}


Table III. Correlations between $D$ score and other variables

\begin{tabular}{|c|c|c|c|c|c|c|c|c|c|}
\hline Variables & \multicolumn{2}{|c|}{ Swimming interest } & \multicolumn{3}{|c|}{ Swimming perceived competence } & Basketball interest & \multicolumn{3}{|c|}{ Basketball perceived competence } \\
\hline$D$ score & \multicolumn{2}{|c|}{$.23^{*}$} & \multicolumn{3}{|c|}{$.24^{* *}$} & $-.19^{*}$ & \multicolumn{3}{|c|}{$-.28^{* *}$} \\
\hline \multicolumn{10}{|c|}{$\begin{array}{l}* p<.01 \\
* * p<.001\end{array}$} \\
\hline & & \multicolumn{2}{|c|}{ Swimming interest } & \multicolumn{2}{|c|}{$\begin{array}{l}\text { Swimming } \\
\text { perceived } \\
\text { competence }\end{array}$} & \multicolumn{2}{|c|}{ Basketball interest } & \multicolumn{2}{|c|}{$\begin{array}{l}\text { Basketball } \\
\text { perceived } \\
\text { competence }\end{array}$} \\
\hline & & $M$ & SD & $M$ & SD & $M$ & $\mathrm{SD}$ & $M$ & $\mathrm{SD}$ \\
\hline \multirow{3}{*}{\multicolumn{2}{|c|}{$\begin{array}{l}\text { 1. Swimmers } \\
\text { 2. Basketball players } \\
\text { 3. Non-sportspersons }\end{array}$}} & 4.82 & 0.35 & 3.96 & 0.71 & 3.38 & 1.04 & 2.21 & 0.90 \\
\hline & & 3.83 & 1.04 & 2.86 & 1.02 & 4.90 & 0.24 & 4.03 & 0.67 \\
\hline & & 3.57 & 1.11 & 2.81 & 1.12 & 2.93 & 1.16 & 2.13 & 1.01 \\
\hline
\end{tabular}

explicit results in the literature related to beliefs about sport ability, evidencing that participation in physical activity was positively related to incremental beliefs (Wang \& Biddle, 2001; Wang et al., 2002). But this study is the first to use implicit measures. The IAT may reveal automatic associations even for subjects who prefer not to express them. With self-report measures such as questionnaires, sportspersons may be reluctant to admit they think that sport ability in their own sport is due to genetic predispositions. In the present IAT, automatic associations between concepts showed that subjects performed faster for their own sport (swimming or basketball) + training than for their own sport + genetics. Consequently, these associations reflected the confidence of swimmers and basketball players about being able to improve and succeed in their sport with training, even when the method was an implicit one, not subject to introspection and social desirability. By contrast, non-sportspersons have no significant automatic association between swimming, basketball, training and genetics. They had no preference for either, whatever the concept. According to Greenwald et al. (2003), there are three ways of interpreting this neutral IAT score. This result could be understood as indicating that non-sportspersons equally associated swimming and basketball with training as much as with genetics, that they equally associated these two sports with training rather than genetics, or that they equally associated both swimming and basketball with genetics rather than training. This last interpretation is in our view the most probable, because entity beliefs were strong predictors of amotivation (Biddle et al., 2003) and people with low or no physical activity were less likely to feel that sport ability was incremental (Wang \& Biddle, 2001; Wang et al., 2002).
Secondly, the results showed that individuals had an automatic association between training and swimming or basketball when they had high perceived competence and interest in this particular sport. In the literature using explicit measures, beliefs about sport ability are often studied in relation to perceived competence and intrinsic interest. Perceived competence is an individual's view of his or her present level of ability (Harter, 1982). It has been shown to be positively related to incremental beliefs (e.g. Biddle et al., 2003; Chian \& Wang, 2008; Cury et al., 2002; Wang \& Biddle, 2001; Wang et al., 2002), but the literature has evidenced no clear pattern of relations with entity theory. Wang and Biddle (2001) evidenced that perceived sport competence is negatively related to entity theory, whereas other studies showed that there was no correlation (e.g. Chian \& Wang, 2008; Cury et al., 2002). The present results evidenced that participants with high perceptions of a particular sport competence tended to automatically associate this sport with training rather than genetics. For example, people with a high perceived competence in swimming implicitly associated swimming with training rather than genetics. This can be attributed to the fact that perceived competence is high because the level reached in this sport is due to countless hours of training. Consequently, this kind of participants considered that sport ability can be improved with training. It might have been found that a high perceived competence in a sport was in line with an implicit association between this sport and genetic stimuli. People could implicitly consider their personal sport competence linked to individual genetic predispositions, and some of them would not dare to recognise it with self-report measures. This is not the case in the present study. With an implicit measure such as 
IAT, social desirability bias can be circumvented, and the results evidenced that the importance of training is deeply embedded among participants who have a high perceived competence in a particular sport. Time spent in sport activities affords opportunities to build sport competencies and, in turn, their selfconcept of their sport abilities (Slutzky \& Simpkins, 2009). Furthermore, when intrinsic interest is high in swimming or in basketball, this sport is automatically associated with training rather than genetics. Intrinsic interest occurs when an individual is doing something for its own sake and not for external rewards (Deci \& Ryan, 1985). In the sport literature, incremental beliefs are predictors of enjoyment and intrinsic motivation and entity beliefs are predictors of amotivation (e.g. Wang et al., 2002; Wang \& Biddle, 2003), whereas in some studies incremental beliefs, but not entity beliefs, were related to intrinsic motivation (Biddle et al., 2003; Chian \& Wang, 2008). According to Wang and Biddle (2001), incremental beliefs are one of the key factors affecting intrinsic motivation and participation in physical activity. This explicit result is reinforced by an implicit measure such as IAT. The automatic association between swimming or basketball and training is stronger when participants have a high intrinsic interest in this sport. People with incremental beliefs about sport ability tended to engage in more adaptive motivational patterns, to increase persistence, and to feel more positive affect. The implicit and automatic association between a sport and training is strongly linked to intrinsic motivation in this sport, reinforcing the importance of developing intrinsic motivation in order to encourage physical activity.

To conclude, it is possible for individuals to hold both entity and incremental views if they believe that both abilities and skills contribute to sport performance (Sarrazin et al., 1996). With an IAT measure, this study highlighted that there is a link between implicit measures and sport practice, which is strengthened when perceived competence and intrinsic motivation in this sport are high. The belief that sport ability is linked to training rather than genetics is deeply ingrained because this association is automatic and less sensitive to social desirability with the use of an implicit measure. However, the direction of this relation is still an open question: is it the source of commitment or is it a consequence of practice? We may think that the experience that someone has developed in a particular sport influences implicit attitudes about sport ability when their underlying automatic evaluation was measured. But it is also possible that initial incremental belief leads the individual to practise sport or physical activity. Similarly, non-sportspersons may think that they do not have enough genetic qualities in swimming and basketball and this may be a reason why they do not practise sport, especially swimming and basketball. But this result may also be one consequence of previous practice of these two sports. If individuals made unsatisfactory progress, they might explain this situation by their lack of genetic qualities and consequently give up sport. Future research could study the direction of this causal relation. As highlighted with swimming and basketball in the present study, the link between implicit measures and the conceptions of swimming and basketball ability should be confirmed with other sports since entity and incremental beliefs may be domain-specific and certainly sport-specific (Dweck et al., 1995; Sarrazin et al., 1996).

\section{Acknowledgements}

We wish to thank Yannick Roux and Lola Rochon $d u$ Verdier who were involved in the data collection.

\section{Disclosure statement}

No potential conflict of interest was reported by the authors.

\section{References}

Biddle, S. J. H., Wang, C. K. J., Chatzisarantis, N. L. D., \& Spray, C. M. (2003). Motivation for physical activity in young people: Entity and incremental beliefs concerning athletic ability. Fournal of Sports Sciences, 21, 973-989.

Blimkie, C. J. R., \& Sale, D. G. (1998). Strength development and trainability during childhood. In E. Van Praagh (Ed.), Pediatric anaerobic performance (pp. 193-224). Champaign, IL: Human Kinetics.

Chen, L. H., Chen, M. Y., Lin, M. S., Kee, Y. H., Kuo, C. F., \& Shui, S. H. (2008). Implicit theories of athletic ability and selfhandicapping in college students. Psychological Reports, 103(2), 476-484.

Chian, L. K. Z., \& Wang, C. K. J. (2008). Motivational profiles of junior college athletes: A cluster analysis. Fournal of Applied Sport Psychology, 20(2), 137-156.

Costill, D. L., Thomas, R., Robergs, R. A., Pascoe, D., Lambert, C., Barr, S., \& Fink, W. J. (1991). Adaptations to swimming training: Influence of training volume. Medicine $\mathcal{E}$ Science in Sports E Exercise, 23(3), 371-377.

Crosby, F., Bromley, S., \& Saxe, L. (1980). Recent unobtrusive studies of Black and White discrimination and prejudice: A literature review. Psychological Bulletin, 87, 546-563.

Crowne, D. P., \& Marlowe, D. (1960). A new scale of social desirability independent of psychopathology. Fournal of Consulting Psychology, 24, 349-354.

Cury, F., Da Fonséca, D., Rufo, M., \& Sarrazin, P. (2002). Perceptions of competence, implicit theory of ability, perception of motivational climate, and achievement goals: A test of the trichotomous conceptualization of endorsement of achievement motivation in the physical education setting. Perceptual and Motor Skills, 95, 233-244. 
Deci, E. L., \& Ryan, R. M. (1985). Intrinsic motivation and selfdetermination in human behavior. New York, NY: Plenum Press.

Durand, M., Cury, F., Sarrazin, P., \& Famose, J. P. (1996). French version of the Robert-Balague perception of success questionnaire. International fournal of Sport Psychology, 27(3), 251-268.

Dweck, C. S. (1986). Motivational processes affecting learning. American Psychologist, 41, 1040-1048.

Dweck, C. S., Chiu, C. Y., \& Hong, Y. Y. (1995). Implicit theories and their role in judgments and reactions: A word from two perspectives. Psychological Inquiry, 6(4), 267-285.

Dweck, C. S., \& Leggett, E. (1988). A social-cognitive approach to motivation and personality. Psychological Review, 95, 256-273.

Greenwald, A. G., \& Banaji, M. R. (1995). Implicit social cognition: Attitudes, self-esteem, and stereotypes. Psychological Review, 102, 4-27.

Greenwald, A. G., McGhee, D. E., \& Schwartz, J. L. K. (1998). Measuring individual differences in implicit cognition: The Implicit Association Test. Fournal of Personality and Social Psychology, 74, 1464-1480.

Greenwald, A. G., Nosek, B. A., \& Banaji, M. R. (2003). Understanding and using the Implicit Association Test: I. An improved scoring algorithm. Fournal of Personality and Social Psychology, 85, 197-216.

Harter, S. (1982). The perceived competence scale for children. Child Development, 53, 87-97.

Hofmann, W., Gawronski, B., Gschwendner, T., Le, H., \& Schmitt, M. (2005). A meta-analysis on the correlation between the Implicit Association Test and explicit self-report measures. Personality and Social Psychology Bulletin, 31(10), 1369-1385.

McAuley, E., Duncan, T., \& Tammen, V. V. (1989). Psychometric properties of the intrinsic motivation inventory in a competitive sport setting: A confirmatory factor analysis. Research Quarterly for Exercise and Sport, 60, 48-58.

Moreno, J. A., Gonzalez-Cutre, D., Martin-Albo, J., \& Cervello, E. (2010). Motivation and performance in physical education:
An experimental test. Fournal of Sports Science and Medicine, 9, 79-85.

Nosek, B. A., Greenwald, A. G., \& Banaji, M. R. (2005). Understanding and using the Implicit Association Test: II. Method variables and construct validity. Personality and Social Psychology Bulletin, 31(2), 166-180.

Ommundsen, Y. (2001). Self-handicapping strategies in physical education classes: The influence of implicit theories of the nature of ability and achievement goal orientations. Psychology of Sport and Exercise, 2, 139-156.

Ommundsen, Y., Haugen, R., \& Lund, T. (2005). Academic selfconcept, implicit theories of ability and self-regulation strategies. Scandinavian Fournal of Educational Research, 49(5), 461-474.

Sallis, J. F., \& Saelens, B. E. (2000). Assessment of physical activity by self-report: Status, limitations, and future directions. Research Quarterly for Exercise and Sport, 71, 1-14.

Sarrazin, P., Biddle, S. J. H., Famose, J. P., Cury, F., Fox, K., \& Durand, M. (1996). Goal orientations and conceptions of the nature of sport ability in children: A social cognitive approach. British Fournal of Social Psychology, 35, 399-414.

Slutzky, C. B., \& Simpkins, S. D. (2009). The link between children's sport participation and self-esteem: Exploring the mediating role of sport self-concept. Psychology of Sport and Exercise, 10, 381-389.

Wang, C. K. J., \& Biddle, S. J. H. (2001). Young people's motivational profiles in physical activity: A cluster analysis. Fournal of Sport and Exercise Psychology, 23, 1-22.

Wang, C. J., \& Biddle, S. J. (2003). Intrinsic motivation towards sports in Singaporean students: The role of sport ability beliefs. Fournal of Health Psychology, 8(5), 515-523.

Wang, C. K. J., Chatzisarantis, N. L. D., Spray, C. M., \& Biddle, S. J. H. (2002). Achievement goal profiles in school physical education: Differences in self-determination, sport ability beliefs, and physical activity. British Fournal of Educational Psychology, 72, 433-445. 